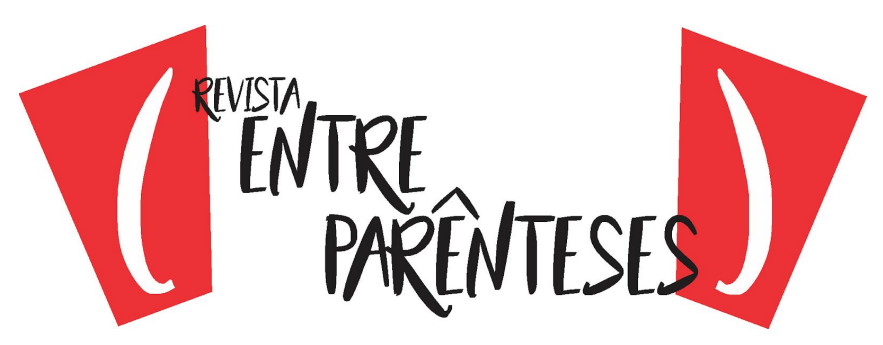

\title{
UMA ANÁLISE SOCIORRETÓRICA DE SEÇÕES DE CONCLUSÃO DE ARTIGOS ACADÊMICOS NA PERSPECTIVA DOS ESTUDOS LINGUÍSTICOS
}

\author{
Francisco Jeimes de Oliveira PAIVA ${ }^{1}$ \\ Universidade Estadual do Ceartá \\ (geimesraulino@yahoo.com.br) \\ Antônio Lailton Moraes DUARTE ${ }^{2}$ \\ Universidade Estadual do Ceará \\ (lailton_duarte@uece.br)
}

\begin{abstract}
Resumo: Neste artigo, como principal objetivo, analisamos e comparamos a descrição sociorretórica da seção de conclusão do gênero artigo acadêmico em atividades de leitura e escrita acadêmicas com alunos do curso de Letras (Língua Portuguesa e Literaturas), a saber, estudantes do último semestre da Faculdade de Filosofia Dom Aureliano Matos/Fafidam. Neste estudo, ancoramo-nos na obra de Bakhtin (1979, 1992, 1997); Swales (1990, 2004); Bhatia (1993, 1997) e, mais especificamente para a análise de gêneros acadêmicos, referentes às pesquisas de Bernardino (2007); Biasi-Rodrigues (1998); Motta-Roth (1995, 2001); Oliveira (2005); Bezerra (2006); Oliveira-Silva; Duarte $(2008,2009)$ acerca da organização retórica de gêneros textuais vinculados à produção do discurso escrito de seus pares na comunidade acadêmica. Para tal empreitada, aplicamos o Modelo CARS de Swales (1990) em um corpus de 10 Artigos Acadêmicos Experimentais (AAEs), no sentido de formalizar um padrão de organização sociorretórica do AAE com base na identificação e classificação das unidades e subunidades caracterizadoras da distribuição de informações em conclusões de AAEs escritos por esses autores/produtores.
\end{abstract}

Palavras-chave: Comunidade Discursiva; Análise Sociorretórica; Artigo Acadêmico Experimental. Seção de Conclusão.

\begin{abstract}
In this article, as main objective, we analyze and compare the sociorretórica description of the section of conclusion of the academic article genre in activities of academic reading and writing with students of the course of letters (Portuguese Language and Literature), namely students of the last semester of the Faculty of Philosophy Dom Aureliano Matos / Fafidam. In this study, we are anchored in the work of Bakhtin (1979, 1992, 1997); Swales (1990, 2004); Bhatia $(1993,1997)$ and, more specifically for the analysis of academic genres, referring to the researches of Bernardino (2007); Biasi-Rodrigues (1998); Motta-Roth (1995, 2001); Oliveira (2005); Bezerra (2006); Oliveira-Silva; Duarte $(2008,2009)$ about the rhetorical organization of textual genres linked to the production of written discourse of their peers in the academic community. For this work, we applied the CARS Model of Swales (1990) in a corpus of 10 AAEs, in order to formalize a pattern of sociorehetoric organization of the SEA based on the identification and classification of the units and subunits

\footnotetext{
${ }_{1}^{1}$ Pesquisador/aluno do Mestrado Interdisciplinar em História e Letras pela Faculdade de Educação, Ciências e Letras do Sertão Central da UECE/MIHL. Graduado em Letras (Língua Portuguesa/Literaturas) pela Universidade Estadual do Ceará. Professor efetivo da SEDUC/CE. E-mail: geimesraulino@yahoo.com.br

${ }^{2}$ Doutorando e mestre pelo Programa de Pós-Graduação em Linguística da UFC. Graduado em Letras e Bacharel em Direito. Professor Assistente e um dos Coordenadores de Área do Programa Institucional de Bolsa de Iniciação à Docência (PIBID) Letras-Português da Faculdade de Filosofia Dom Aureliano Matos, de Limoeiro do Norte da Universidade Estadual do Ceará. Bolsista CNPq. E-mail: lailton_duarte@uece.br
} 


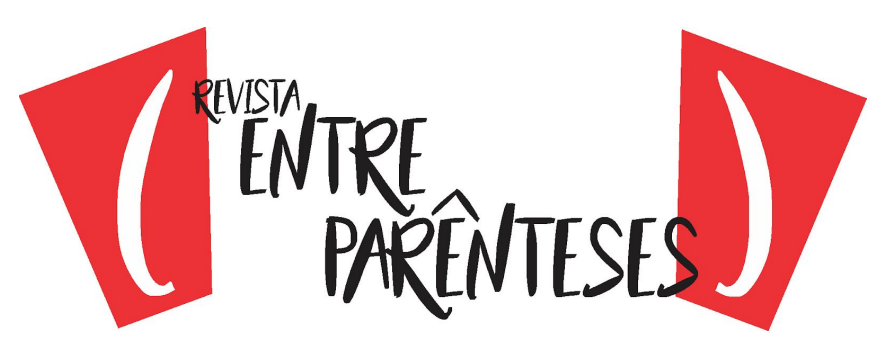

characterizing the distribution of information in the conclusions of SEAs written by these authors / producers.

Keywords: Discursive Community; Sociorethoric Analysis; Experimental Academic Article. Conclusion Section.

Resumen: En este artículo, el objetivo principal, analizar y comparar la descripción de la sección sociorretórica conclusión del artículo género académico en actividades de lectura y escritura académica con las letras de los estudiantes del curso (en inglés y literatura del idioma), es decir, los estudiantes último semestre de la Facultad de Filosofía Dom Aureliano Matos / Fafidam. En este estudio, nos anclamos en la obra de Bakhtin (1979, 1992, 1997); Swales (1990, 2004); Bhatia (1993, 1997) y, más específicamente para el análisis de géneros académicos, referentes a las investigaciones de Bernardino (2007); Biasi-Rodrigues (1998); Motta-Roth (1995, 2001); Oliveira (2005); Bezerra (2006); Oliveira-Silva; Duarte $(2008,2009)$ acerca de la organización retórica de géneros textuales vinculados a la producción del discurso escrito de sus pares en la comunidad académica. Para este trabajo, aplicamos el modelo CARS de Swales (1990) en un corpus de 10 AAEs, en el sentido de formalizar un patrón de organización sociorretórica del AAE con base en la identificación y clasificación de las unidades y subunidades caracterizadoras de la distribución de informaciones en conclusiones de EAEs escritos por esos autores / produtores.

Palabras-clave: Comunidad Discursiva; Análisis Socioretórica; Artículo Académico Experimental. Sección de Conclusión

\section{Introdução}

Em recentes estudos, Paiva e Duarte $\left(2011,{ }^{3} 2017\right)$ conseguiram formalizar, a partir da expansão da proposta de organização sociorretórica de artigos científicos de Motta-Roth (2001), à luz da perspectiva da abordagem sociorretórica de estudos de gêneros de Swales (1990), um modelo de análise crítica de gênero (ACG) em artigos acadêmicos experimentais (AAEs) escritos por estudantes concludentes do curso de Letras (Língua Portuguesa) da Universidade Estadual do Ceará. Dessa feita, tornou-se evidente o quão necessárias são as pesquisas para investigação e descrição das práticas discursivas e de compreensão das práticas de letramentos acadêmicos, em consonância das experiências de escrita desses sujeitos/produtores nas atividades retóricas de escrita universitária na contemporaneidade.

Sabe-se que, na área de investigação da ciência linguística, bem como nas ciências sociais e humanas, lato sensu, a noção de gênero discursivo tem granjeado uma análise peculiar, em um reconhecimento explícito de sua potencialidade para

\footnotetext{
${ }^{3}$ Resultado de pesquisa e coleta de corpus durante as atividades como bolsista - Programa de Monitoria acadêmica (PROMAC), da Universidade Estadual do Ceará na Fafidam/UECE.
} 


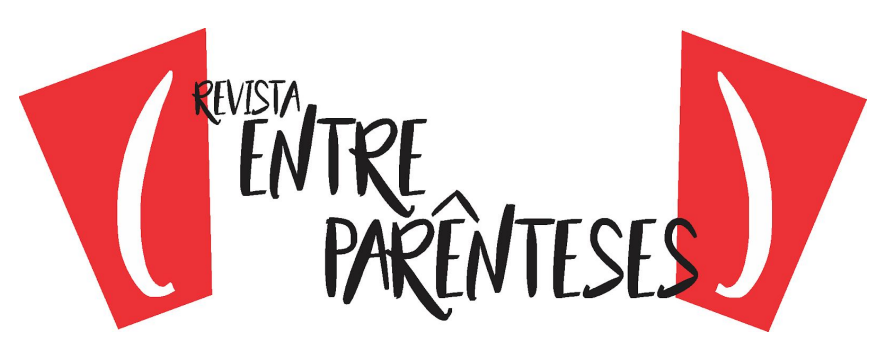

uma análise integrada não só do processo e do produto textual/discursivo em si, mas também, e necessariamente, de seu papel como expressão privilegiada de práticas com todas as suas implicações (BEZERRA, 2006). Por isso, deu-se tanta importância tanto à interação sociocomunicativa, ${ }^{4}$ como também aos conflitos resultantes de relações de poder e de ideologias nas diferentes instâncias de atuação humana, manifestando-se e atualizando-se por intermédio de textos diversos, que, por sua vez, assumem a configuração de gêneros particulares e convencionalizados (PAIVA, 2011; PAIVA; DUARTE, 2017).

Nesse sentido, os estudos sobre gêneros discursivos têm crescido muito, haja vista muitas pesquisas assinalarem novas perspectivas de se avaliar o fenômeno da lingua(gem). Dessa forma, a Análise de Gêneros, em outras palavras, vem propiciando contribuições teórico-metodológicas para avançar na descrição do crescente número de "novos" gêneros que vêm sendo praticados nos mais diversos contextos de produção de uma determinada comunidade discursiva. ${ }^{5}$

Marcuschi (2002) salienta que essas formas discursivas são novas, tais como editoriais, artigos de fundo, notícias, telefonemas, telegramas, telemensagens, teleconferências, videoconferências, reportagens ao vivo, cartas eletrônicas (e-mails), bate-papos virtuais, aulas virtuais e assim por diante. Seguramente, esses novos gêneros não são inovações absolutas, quais criações ab ovo, sem uma ancoragem em outros gêneros já existentes. O fato já fora notado por Bakhtin (1997, p.295) que falava na 'transmutação' dos gêneros e na assimilação de um gênero por outro, gerando outro gênero.

\footnotetext{
${ }^{4}$ Machado (2005) quanto a esse assunto discute que as relações interativas são processos produtivos de linguagem. Consequentemente, gêneros e discursos passam a ser focalizados como esferas de uso da linguagem verbal ou da comunicação fundada na palavra.

${ }^{5}$ A noção de comunidade discursiva acadêmica é empregada por professores e pesquisadores que têm a visão de produção de texto como sendo uma atividade social, realizada por comunidades que têm convenções específicas e para as quais o discurso faz parte de seu comportamento social. Dentro dessa visão, com a qual Swales (1990) se afina, o discurso é a expressão do conhecimento do grupo. As convenções discursivas são o meio para a iniciação de membros novos na comunidade, isto é, os novatos são levados a usar de forma apropriada as convenções discursivas reconhecidas pela comunidade (HEMAIS; BIASI-RODRIGUES, 2005).
} 


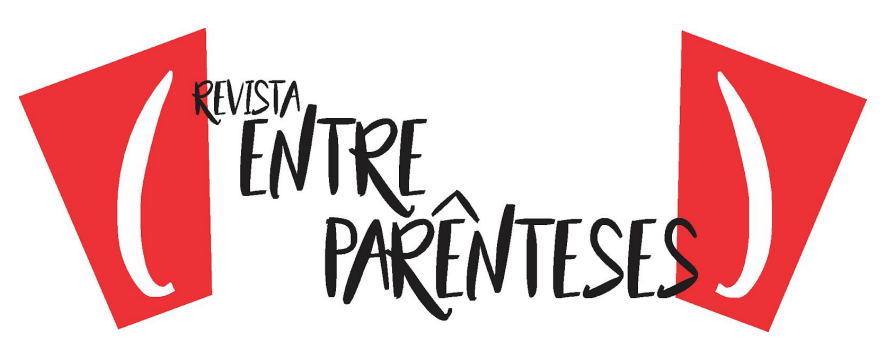

Nesta pesquisa, basear-nos-emos fundamentalmente em Bakhtin (1997) e Swales (1990). O primeiro estudioso porque é, por certo, menção indispensável para os estudos dos gêneros, já que ele é criador da designação gênero do discurso. E o segundo autor pelo fato de nos oferecer uma abordagem teórico-conceitual para determinarmos critérios para análise de gêneros discursivos e de comunidade discursiva (SWALES, 1990); para revisitarmos as características de comunidade discursiva (SWALES, 1992, 1993, 1998), e do papel do propósito comunicativo no (re)conhecimento de gêneros (ASAKEHAVE; SWALES, 2001, ${ }^{6}$ SWALES, 2004). E, por fim, aplicamos o modelo $C A R S^{7}$ (SWALES, 1990) em um corpus de exemplares de Artigos Acadêmicos Experimentais (doravante AAEs) coletados dos alunos do nono semestre do Curso de Graduação em Letras, de uma faculdade localizada no Estado do Ceará, no período de setembro de 2017 a janeiro de 2018.

Aplicamos, neste estudo, a Teoria Dialógica de Discurso (TDD) ${ }^{8}$ de Bakhtin (1992) que se faz necessária para as análises de gêneros do discurso empreendidas nos estudos da lingua(gem), textos e discursos nas sociedades pós-modernas. Primeiro, porque esse autor, além de fundar a denominação gênero do discurso, fez também a caracterização dos aspectos que compõem os gêneros do discurso, como sendo: conteúdo temático; estilo e construção composicional, que são pontos

${ }^{6}$ C.f. ASKEHAVE; SWALES (2001, p. 195-212).

${ }^{7}$ O Modelo CARS de Swales (1990) é conceituado, segundo Oliveira (2005), como "a forma de um modelo constituído de moves \{movimentos\} e steps \{passos\} (subunidades moves). Neste modelo, denominado modelo CARS (creating a research space [criar um espaço para pesquisa]) para introduções de artigos de pesquisa, Swales (1990) apresenta um quadro de categorias passíveis de aparecer em introduções de artigos de pesquisa. As categorias fundamentais, denominadas moves, mais genéricas, são preenchidas por subcategorias, às vezes optativas entre si, denominadas steps, sendo que para sua pesquisa adota as denominações utilizadas por Biasi-Rodrigues (1998), a saber: unidades e subunidades retóricas, por entender que tais designações evidenciam, de imediato, as complexas relações retóricas presentes em cada um dos moves e dos steps que compõem e caracterizam o gênero textual resumo acadêmico, seu objeto de estudo.

${ }^{8}$ Brait (2006, p. 10) explica que a "teoria dialógica do discurso" (TDD), sem uma definição fechada, o que seria uma contradição com o próprio conceito teórico, "[...] a indissolúvel relação existente entre língua, linguagens, história e sujeitos que instaura os estudos da linguagem como lugares de produção de conhecimento de forma comprometida, responsável, e não apenas como procedimento submetido a teorias e metodologias dominantes em determinadas épocas". Esse embasamento constitutivo diz respeito a uma concepção de linguagem, de construção e produção de sentidos necessariamente apoiadas nas relações discursivas empreendidas por sujeitos historicamente situados. 


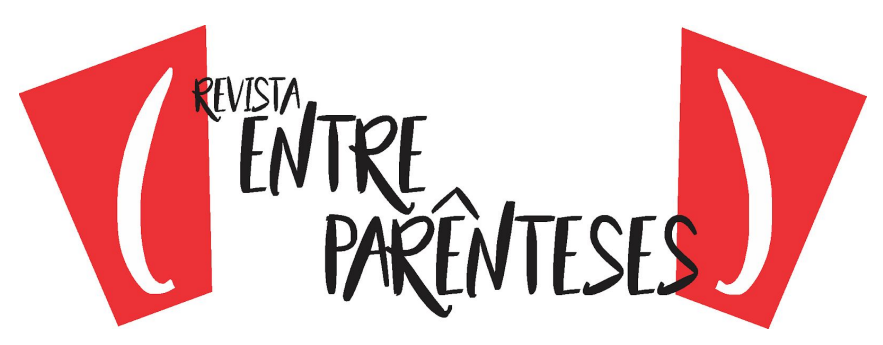

primordiais para estudos que busquem descrever um gênero discursivo seja lá qual for. Nessa perspectiva bakhtiniana, compreendemos que os gêneros são vistos como fenômenos contextualmente situados e construídos na interação comunicativa, sendo entendidos a partir de sua natureza sócio-histórico-cultural.

Em outras palavras, é de Bakhtin (1992) que temos a ideia de relação indissociável entre gênero de discurso e esfera da atividade humana em que é produzida. Por fim, aprendemos dos ensinos de Bakhtin que há gêneros mais padronizados e estereotipados e gêneros mais maleáveis, plásticos e criativos. Sendo assim, os gêneros possuem a capacidade de serem reestruturados criativamente de acordo com a habilidade e a competência de seus produtores/consumidores.

Além do mais, John Swales $(1981,1990)$ com sua perspectiva sociorretórica nos oferece conceitos-chave para o reconhecimento dos gêneros discursivos e das práticas sociais que os envolvem, sendo que a aplicação da sua teoria tem propiciado a construção de subsídios para que os sujeitos/autores da comunidade discursiva acadêmica exercitem esse reconhecimento, identificando as características formais e funcionais, culminando no desenvolvimento da capacidade de produzir textos que realizem com eficácia seus propósitos comunicativos, de acordo com o gênero a que pertencem.

Neste artigo, enfim, consideramos Swales (1990) também como referencial por ser criador do construto teórico, alcunhado modelo CARS. Isso significa que os estudos desse autor, de acordo com Bernardino (2007) a noção de gênero discursivo está intimamente ligada ao conceito de comunidade discursiva que tem como principal critério de classificação o reconhecimento dos propósitos comunicativos comuns e partilhados que regulam a interação.

Por fim, nosso objetivo, pautou-se em construir um modelo sociorretórico de análise do gênero (AAE) escrito por concludentes do curso de Letras (língua portuguesa), com base nas orientações e práticas efetivas de letramentos 


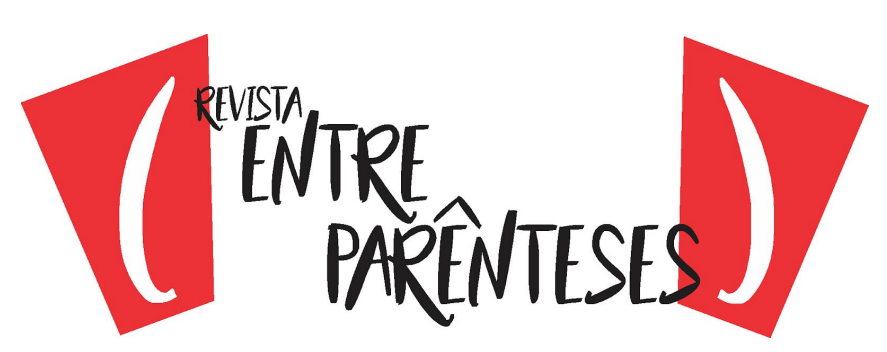

acadêmicos em escrita requeridas pela comunidade discursiva acadêmica (doravante CDA).

\section{Gêneros discursivos: perspectivas teóricas e novas tendências de estudo na comunidade discursiva acadêmica (CDA): alguns apontamentos}

Bakhtin (1997) foi fundador da terminologia gênero do discurso que presentemente baseia a maioria das pesquisas sobre gêneros discursivos. Isto significa que a gigantesca multiplicidade de possibilidades de uso da língua em vários contextos da atividade humana está diretamente ligada à análise crítica dos gêneros do discurso, nesse sentido, ele assegura que,

[t]odas as esferas da atividade humana, por mais variadas que sejam, estão sempre relacionadas com a utilização da língua. Não é de surpreender que o caráter e os modos dessa utilização sejam tão variados como as esferas da atividade humana (BAKHTIN, 1997, p. 279).

$\mathrm{Na}$ abordagem bakhtiniana, o uso da língua realiza-se em forma de enunciados orais e escritos, em razão da esfera da atividade humana em que os enunciados sejam materializados, logo é perceptível à ocorrência de tipos relativamente estáveis de enunciados. Por serem tão variados, há a necessidade de a língua colocar essa relativa estabilidade, para que, dependendo do lugar de produção, os gêneros se caracterizem e/ou se ampliem, como ele mesmo diz,

[a] riqueza e a variedade dos gêneros do discurso são infinitas, pois a variedade virtual da atividade humana é inesgotável, e cada esfera dessa atividade comporta um repertório de gêneros do discurso que vai diferenciando-se, ampliando-se à medida que a própria esfera se desenvolve e fica mais complexa (BAKHTIN, 1997, p. 279).

Esse estudioso, quando aborda essa questão da abundância de gêneros do discurso menciona que essa relativa padronização transfere caráter específico e permite que a comunicação advenha de forma clara e objetiva independentemente 


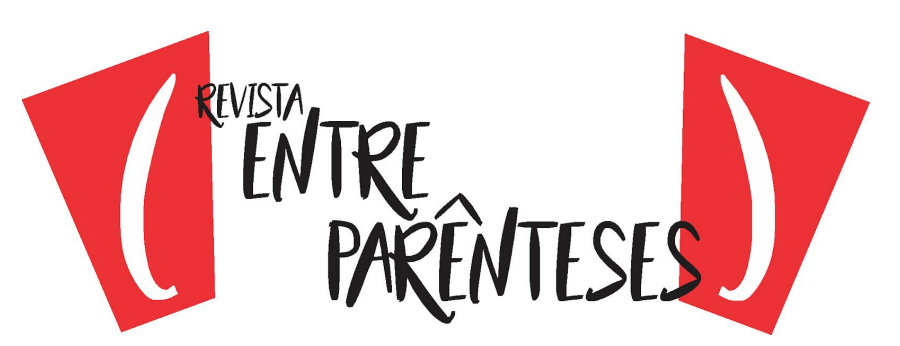

do local de sua produção. Como nesta pesquisa, descrevemos a estrutura de um gênero textual que se realiza como produção de uma determinada comunidade discursiva, ponderamos que o enfoque da teoria dialógica de Bakhtin tornou-se categórico para que incluamos o conhecimento da cadeia em que está incluído o gênero discursivo em análise.

\section{O modelo CARS: uma análise de gêneros na perspectiva sociorretórica}

Quanto à perspectiva de Swales (1990, 2001), a Análise de Gêneros no bojo da análise da organização sociorretórica está conexa com a natureza da informação e o modo como o autor coloca essas informações em unidades discursivas para atuar em determinada situação sociorretórica. Dessa forma, a fim de ensinar produção textual e leitura de uma forma contextualizada, Swales (1990) desenvolveu o modelo CARS para analisar a organização sociorretórica ${ }^{9}$ de introduções de artigos de pesquisa. Neste modelo descritivo, o autor baseou-se de dois conceitos: o de movimento/movement (grande ação retórica atingida no texto) e o de passo/step (sub-ação que consegue o movimento).

No entanto, em uma primeira versão, o modelo ofereceu quatro movimentos: 1) Estabelecendo o campo de pesquisa (área em que se insere a pesquisa); 2) Sumarizando pesquisas prévias (faz referência a pesquisas já desenvolvidas); 3) Preparando a presente pesquisa (descreve a pesquisa, indicando objetivos, hipótese e métodos); e, finalmente, 4) Introduzindo a presente pesquisa (mostra aspectos relevantes na área desenvolvida).

Por causa de alguns(mas) pesquisadores(as) escreverem sobre suas dificuldades em separar o movimento 1 do movimento 2, Swales (1990) revisou o modelo inicial e o atualizou, abreviando de 4 para 3 os movimentos retóricos das introduções de artigos de pesquisa, porém adicionando diversos passos em cada um dos movimentos, segundo mostra a figura 1 a seguir:

\footnotetext{
${ }^{9}$ Swales (1990) entende a organização retórica, como sendo o modo como o texto realiza propósitos comunicativos.
} 


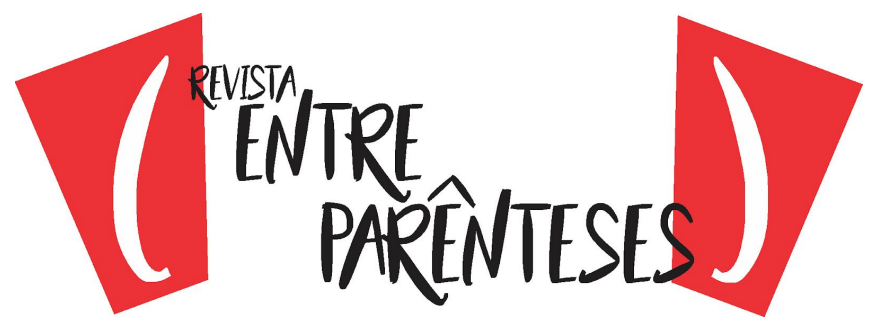

\begin{tabular}{|c|c|c|}
\hline \\
\hline \multicolumn{3}{|c|}{$\begin{array}{l}\text { MOVIMENT O 1: ESTABELECER O TERRITORIO } \\
\text { Passo } 1 \text { - Estabelecer a importância da pesquisa }\end{array}$} \\
\hline Fasso 2 - Fazer generalizacão/öes quanto ao tópico & eloul & \\
\hline Passo 3 - Revisar a literatura (pesquisas prérias) & & $\begin{array}{l}\text { Diminuindo o } \\
\text { esforço retortico }\end{array}$ \\
\hline \multicolumn{3}{|l|}{ MOVIMENT O 2: ESTABELECER O NICHO } \\
\hline Passo 1A - Contra-argumentar & oul & \\
\hline Passo 1B - Indicar lacuna/s no conhecimento & oul & \\
\hline Passo 1C - Provocar questionamento & out & Enfiaquecendo \\
\hline Passo 1D - Continuara tra diça & & $\begin{array}{l}\text { os possiveis } \\
\text { questionamentos }\end{array}$ \\
\hline \multicolumn{3}{|l|}{ MOVIMENT O 3: OCUPAR O NICHO } \\
\hline Passo 1A - Delinear os objetivos & oul & 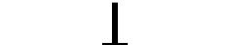 \\
\hline Passo 1B - Apresentar a pesquisa & & \\
\hline Passo 2 - Apresentar os principais resultados & & Explicitando \\
\hline Passo 3 - Indicar a estrutura do artigo & & o trabalho \\
\hline
\end{tabular}

Figura 1 - Descrição da organização sociorretórica da seção introdutória de artigos acadêmicos (SWALES, 1990, p. 141)

Esse modelo assinala uma composição textual estabelecida de três movimentos sociorretóricos, atestados com diferentes passos, que cumprem funções particulares, conexas ao propósito comunicativo da estrutura prototípica por ele descrita. Os três movimentos retóricos são propostos pelo autor como obrigatórios em introduções de artigos de pesquisa, entretanto as partículas e/ou e ou que surgem entre os passos indicam a opcionalidade destes. As setas assinalando para baixo advertem o movimento de organização das informações, do geral para o particular, em razão do esforço retórico realizado para se chegar aos aspectos característicos que constituem a pesquisa em tela.

A utilização do modelo CARS nos permitiu recomendar ao final desta pesquisa um modelo de organização sociorretórica dos AAEs. Deste modo, esse modelo nos consentiu, através da observação dos propósitos comunicativos de cada unidade sociorretórica, identificar e classificar as unidades e subunidades sociorretóricas presentes da distribuição de informações em AAEs, produzidos por alunos concludentes do Curso de Graduação em Letras, visando à verificação da organização sociorretórica desses gêneros escritos nesse espaço de produção escrita de textos acadêmicos. 


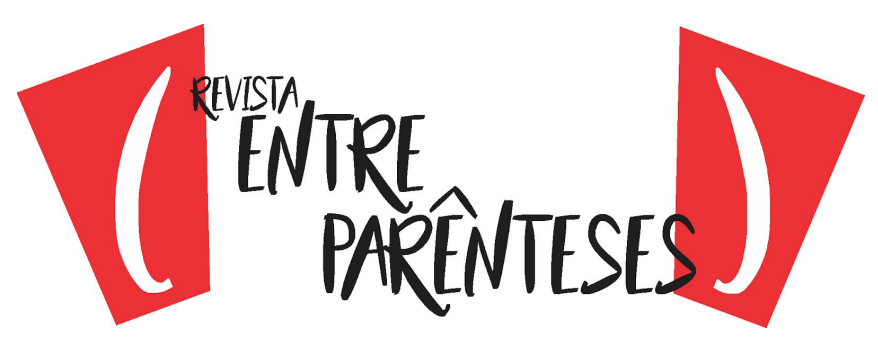

Nesse diapasão, em síntese, destacamos que a identificação das unidades sociorretóricas caracterizadoras dessa espécie/modalidade de artigo acadêmico, resultado da aplicação do modelo proposto por Swales (1990) nos equipou com mais elementos que colaboraram para a caracterização do gênero artigo acadêmico experimental, construindo um modelo de análise crítica de gêneros (ACD) de textos produzidos por estudantes de graduação.

\section{Descrevendo o gênero artigo acadêmico experimental (AAE): ensinando, negociando e compartilhando conhecimentos}

Swales (1990) concebe os AAEs como textos escritos que contêm também textos não-verbais (tabelas, gráficos, figuras, esquemas e diagramas), comumente limitado a mais ou menos 10.000 palavras, cujo objetivo são reproduzirem os resultados de estudo(s)/pesquisa(s) realizado(s) por um pesquisador/a ou um grupo de pesquisadores/as.

Vale destacar que, dentro do domínio da CDA, o gênero AAE, segundo Hyland (2000) possui a encargo de estabelecer a produção científica em questão com caráter de inovação para a comunidade disciplinar, perfilhando as produções anteriores e estabelecendo as hipóteses em questão dentro do contexto geral do discurso disciplinar.

Além de proporcionar credibilidade sobre as proposições construídas no artigo, comprovando e construindo o $e^{2} \operatorname{sos}^{10}$ disciplinar adequado e pautando-se em habilidades para negociar com os pares da academia os saberes imprescindíveis ao desenvolvimento científico e ao exercício das práticas de letramentos necessários em escrita e leitura de textos acadêmicos.

\footnotetext{
${ }^{10}$ Segundo Maingueneau (2001), ethos é o fenômeno em que, "por meio da enunciação, revela-se a personalidade do enunciador". "São os traços de caráter que o orador deve mostrar ao auditório (pouco importa sua sinceridade) para causar boa impressão: são os ares que assume ao se apresentar. [...] O orador enuncia uma informação, e ao mesmo tempo diz: eu sou isto, eu não sou aquilo" (MAINGUENEAU, 2001, p. 98).
} 


\section{Propósitos comunicativos}

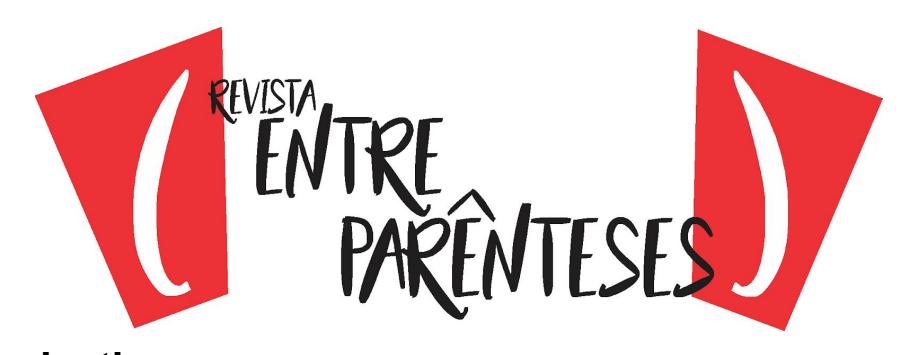

Com base nos estudos de Bhatia (1993; 1997), apud Bezerra (2006, p. 70), o propósito comunicativo veicula-se justamente com aquilo que os gêneros alcançam na sociedade, admitindo-se, todavia, que o propósito de um gênero não é fundamentalmente único e pré-determinado. No conjunto de propósitos comunicativos concretizados por um gênero, existirá propósitos específicos ou "intenções particulares" de certos atores sociais, sejam eles os produtores/consumidores do gênero ou os controladores de sua produção e circulação, como no caso dos gêneros da mídia, por exemplo, ao lado dos propósitos "socialmente reconhecidos".

\section{Aspectos estilísticos}

Para Bakhtin (1979, p. 283), o estilo "está intimamente ligado ao enunciado e a formas típicas de enunciados, isto é, aos gêneros do discurso", isto é, o vínculo indissociável, orgânico, entre o estilo e o gênero mostra-se com muita clareza quando se aborda do estilo linguístico ou funcional. De fato, o estilo linguístico ou funcional nada mais é senão o estilo de um gênero peculiar a uma esfera da atividade e da comunicação humanas.

Verificando os manuais de metodologia científica, observa-se que o estilo ganha acentuado destaque. Isso, entretanto, não impede que o estilo seja levemente descrito ao longo das prescrições. Uma plausível justificativa para sua presença nos manuais é o fato de fazer parte da constituição do gênero, estando indissoluvelmente unido ao enunciado, sendo assim, Bakhtin (2003) nos diz que esses enunciados conjeturam as condições específicas e as finalidades de cada referido campo não só por seu conteúdo (temático) e pelo estilo da linguagem, ou seja, pela seleção dos recursos lexicais, fraseológicos e gramaticais da língua. 


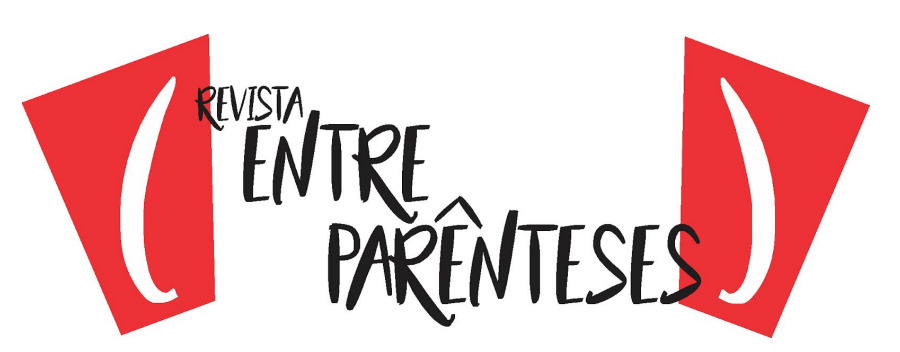

Em resumo, o estilo está presente em todo enunciado, proporcionando duas concepções, segundo o filósofo russo, enquanto expressão da individualidade do falante e enquanto estilo do próprio gênero do discurso. Sendo, portanto, esse autor indica que o estilo do enunciado é determinado pela relação valorativa do falante com o elemento semântico objetal do enunciado, ou seja, o falante possui suas emoções, seus juízos de valor, que definem sua relação com o elemento semântico-objetal.

\section{Estrutura composicional}

Swales (1990) determina o gênero AAE como um texto escrito (embora, repetidamente, contenha elementos não verbais), comumente concentrado a alguns milhares de palavras, que reporta a alguma investigação feita por seu autor ou autores. Além do mais, o AAE irá, em regra, relacionar as descobertas exibidas por ele às dos outros pesquisadores e pode, também, expor questões teóricas ou metodológicas. Esse gênero é publicado/disposto em revistas acadêmicas ou, menos caracteristicamente, editado em um livro composto de artigos escolhidos.

Em sua análise do gênero discursivo AAE, Swales (1990) segue a estrutura textual desmembrada nas seções de Introdução, Métodos, Resultados e Discussão ou IMRD, originalmente sugerido por Swales (1990). Essa divisão do AAE conjetura a organização da pesquisa, ou seja, os passos adotados para sua realização e também permite o direcionamento do/a leitor/a para os pontos de seu interesse no texto.

A estrutura IMRD tornou-se modelo para o AAE, por ajustar-se aos relatos originais de pesquisa e/ou seguir "o ciclo lógico da pesquisa indutiva" (DODD, 1986, p.2). Tal composição textual parece promover a leitura rápida, vindo esse aspecto a ser importante para os cientistas que, a cada dia, necessitam ler mais material de forma cada vez mais acelerada. Essa constância estrutural do AAE comprova que esse texto oferece uma relativa organização com informações; contudo, tão-somente 


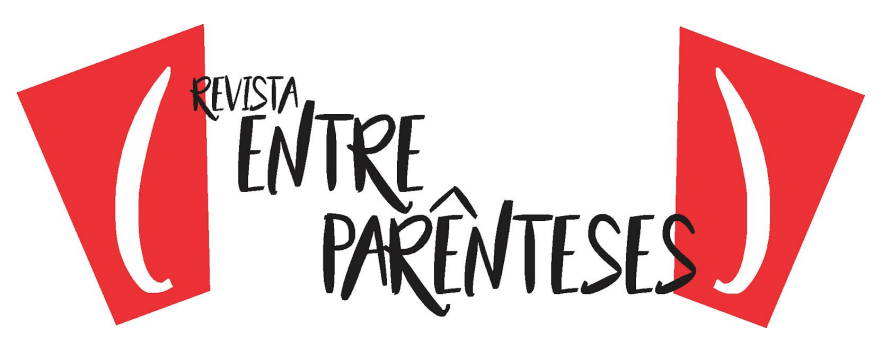

organizar procedimentos de uma pesquisa não é suficiente; o autor/articulista deve fazer com que seu leitor/a apreenda e aprove seu trabalho.

Enfim, os gêneros discursivos produzidos pela comunidade acadêmica possuem características particulares, convencionalmente determinadas, que constituem fatores restritivos na definição da sua forma em cada situação comunicativa, ou seja, a estabilidade de um gênero, por isso, é garantida em larga medida pela sua estrutura interna convencionalizada, que é, segundo Bhatia (1993), apud Bezerra (2006), "resultado cumulativo da experiência e/ou do treinamento dentro da comunidade de especialistas".

\section{O trajeto analítico-metodológico adotado}

Expomos neste momento, a perspectiva teórica definida para esta pesquisa, sendo assim, os objetivos traçados para esse estudo no contexto de produção escrita de gêneros discursivos do domínio acadêmico que foram cruciais, para que os aspectos analisados e as nossas hipóteses levantadas pudessem contribuir para a escolha da pesquisa qualitativa, ${ }^{11}$ uma vez que o foco desta natureza de pesquisa nos oferece uma obtenção de corpus mediante contato direto e interativo do pesquisador com o objeto de estudo (PAIVA, 2011).

Dessa forma, assinalamos os procedimentos de análise, porque como assegura Marcuschi (1999)

[o] essencial [em pesquisa] é que se tenham presentes, sempre, os objetivos da investigação e que em todos os casos se ande bem calçado por uma teoria de base. O perigo maior não está propriamente na metodologia adotada e sim na falta de uma perspectiva teórica definida (MARCUSCHI, 1999, p. 47, com acréscimos).

\footnotetext{
11 Segundo Lakatos e Marconi (2007), na abordagem qualitativa, a pesquisa tem o ambiente como fonte direta dos dados. $\mathrm{O}$ pesquisador mantém contato direto com o ambiente e objeto de estudo em questão necessitando um trabalho mais intensivo de campo. Neste caso, as questões são estudadas no ambiente em que eles se apresentam sem qualquer manipulação intencional do pesquisador. Os dados coletados nessas pesquisas são descritivos, retratando o maior número possível de elementos existentes na realidade estudada.
} 


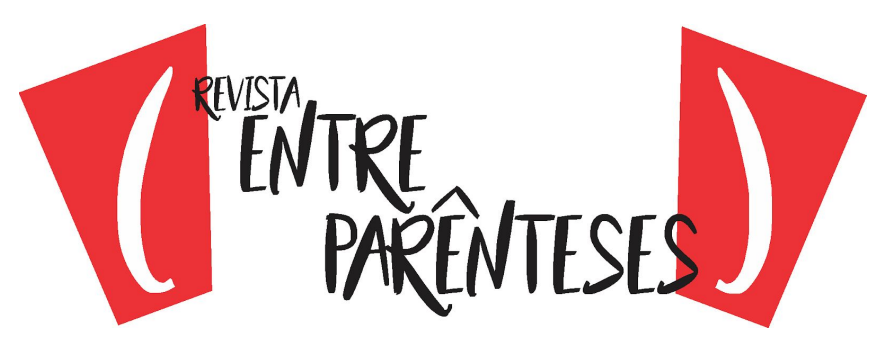

Isto significa que a prioridade da pesquisa é ter um referencial teórico que dê suporte às hipóteses, análises e/ou resultados obtidos. Quando esse referencial é obtido, temos por consequência direta uma metodologia com possibilidades reais de aplicação e de obtenção de resultados efetivos. E essa é a nossa pretensão, tanto que, nesta seção, apresentaremos os referenciais teóricos que dão alicerce ao nosso estudo.

\section{A caracterização da análise do corpus}

O corpus desta pesquisa foi composto de 10 Conclusões de (AAEs) produzidos por alunos concludentes do Curso de Graduação em Letras de uma faculdade do Ceará, no período de 2016 a 2017, em Limoeiro do Norte/CE.

Apesar de não ser um corpus quantitativamente extenso, consideramos ser um número de exemplares de AAEs suficiente para os objetivos da pesquisa. Essa afirmação está em Marcuschi (1999) quando o autor lembra que,

[...] do ponto de vista metodológico, constituir um corpus é uma questão bastante complexa e, em primeira instância, teórica, sendo que o tamanho de um problema não se mede pela quantidade de dados coletados, mas por sua qualidade. Uma observação singular ou um dado privilegiado pode ser suficiente para produzir um grande número de observações teóricas produtivas (MARCUSCHI, 1999, p. 56).

Isto quer dizer que a qualidade da pesquisa não está inteiramente relacionada à quantidade de dados coletados. O que determina essa qualidade é o número de observações teóricas produtivas que a pesquisa venha a produzir.

Como já explanamos neste trabalho, adotamos para fins de análise, a fase escrita do gênero discursivo artigo acadêmico experimental (AAE), justificando esta escolha por questões metodológicas, pois o trabalho se objetivou descrever e construir uma organização sociorretórica do gênero AAE produzido por alunos concludentes do Curso de Graduação. Por conta do corpus existente, os exemplares 


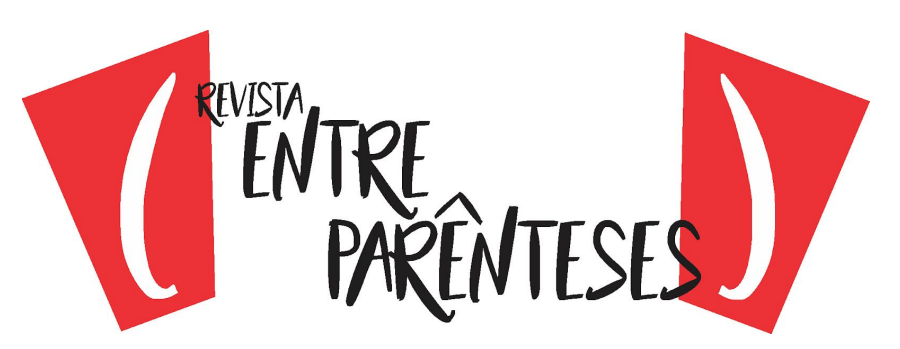

pesquisados já haviam sido escritos anteriormente nas disciplinas ministradas pelos professores do referido campo de conhecimento disciplinar.

\section{Convenções e considerações adotadas}

Para a realização dos objetivos deste trabalho, as convenções e considerações a seguir expostas deverão ser observadas:

1) todos os produtores dos gêneros textuais artigo acadêmico experimental não serão identificados, visto que a maioria dos escritores iniciantes apresentam dificuldades de produção escrita desse gênero quanto à metodologia de produção, planejamento e organização desses textos acadêmicos em relação às orientações dos manuais de metodologia científica, ABNT e normatizações da própria Instituição de Ensino Superior (IES).

2) todos os exemplares passarão a ser identificados da seguinte forma: AAE1, AAE2, AAE3 até o AAE10, em que AAE1 significa artigo acadêmico experimental 1, de acordo com a disposição dos exemplares de artigos acadêmicos experimentais que seguem arrolados em anexo e assim segue, sucessivamente, a identificação.

3) adotaremos, em nosso trabalho, as denominações utilizadas por Biasi-Rodrigues (1998), e por Oliveira (2005), que são: unidades e subunidades retóricas em detrimento ao que Swales (1990) originalmente decidiu designar por moves e steps.

4) quando houver a necessidade de utilização de quadros que sintetizem a ocorrência de unidades retóricas, essas serão identificadas como UR1, UR2 etc.

Por fim, segundo Jucá (2006), entendemos que cada bloco textual correspondente às subunidades realizadas, como ele fez/adotou nas seções de justificativa analisadas, é delimitado por uma linha horizontal, que tem extensão maior que o próprio texto. Na parte direita desta linha horizontal indicamos a unidade retórica a que pertence a porção textual e na esquerda a subunidade em que esta unidade retórica está sendo realizada. 


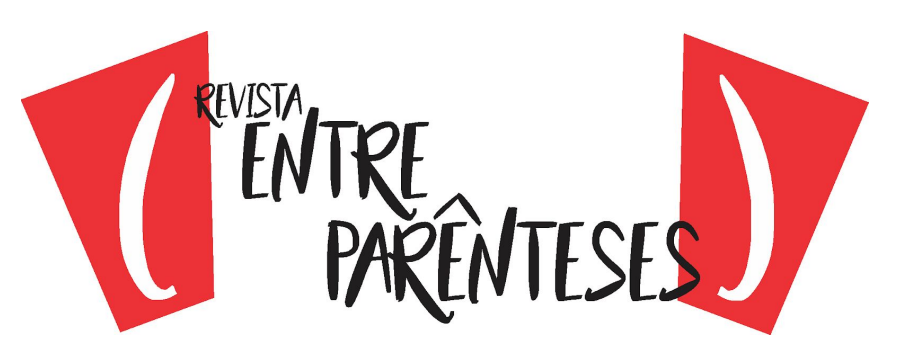

Cada unidade retórica identificada é representada pelo símbolo "Un" acompanhado de um número cardinal (ex. Un1) e cada subunidade é representada apenas pelo seu número, de acordo com a unidade retórica a que pertence (ex. S1.1, S2.2, S3.1 etc.).

As unidades ou subunidades, cuja informação não conseguimos identificar, são representadas pelo sinal "?" e aquelas cuja informação aparece apenas sugerida, são representadas pelo sinal "!", acompanhando a representação da unidade ou subunidade sugerida, seguindo a orientação metodológica, desenvolvida por Biasi-Rodrigues (1998), por (ex:Un1! / 1.1!).

\begin{tabular}{|l|l|l|}
\hline Un1 & $\begin{array}{l}\text { Texto texto texto texto texto texto texto texto texto } \\
\text { texto texto texto texto } \\
\text { texto texto texto texto texto texto texto texto texto } \\
\text { texto texto texto texto } \\
\text { texto texto texto texto }\end{array}$ & S1.1 \\
\hline
\end{tabular}

Quadro 1 - Modelo de segmentação para análise de seções de AAE's.

Da análise do corpus a uma leitura dos aspectos léxico-gramaticais na organização sociorretórica das seções de conclusões dos AAEs

Neste momento, analisamos e construímos a caracterização discursiva e linguística da seção de conclusões dos AAEs a partir dos elementos léxico-gramaticais convencionalmente presentes nos excertos dos 10 artigos avaliados e que resultaram na organização sociorretórica da conclusões de pesquisa nos AAEs, demonstrando a relativa estabilidade na perspectiva de estudos de gêneros discursivos bakhtinianos, bem como maior organização da estrutura composicional destas seções em AAEs produzidos nas atividades de escrita no domínio acadêmico.

Vejamos agora, a segmentação das conclusões selecionadas:

AAE 1 - SEÇÃO DE CONCLUSÃO(ÕES)

(9) Unidade: CONCLUIR A PESQUISA 


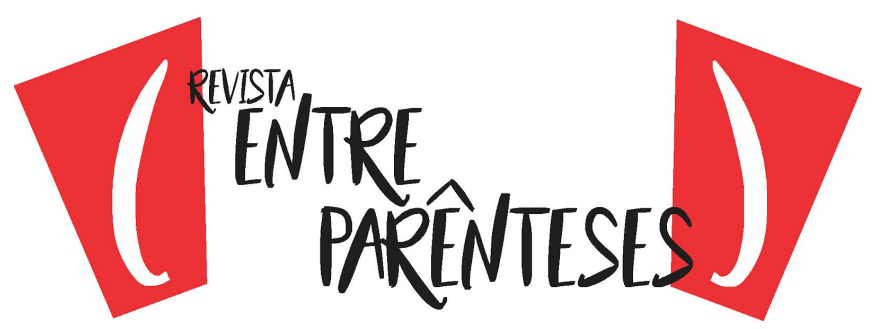

Subunidade 1A - apresentando conclusão(ões)

Subunidade 1B - relacionando os resultados a área investigada

Subunidade 2 - apontando contribuição(ões) da pesquisa

Subunidade 3 - apresentando as lacunas da pesquisa

Obs.:

É importante lembrar que geralmente esta seção de conclusao(ões) está IMBRICADA e/ou INTERCALADA (?) na seção de Discussão e Resultados, por isso o modelo Motta-Rothiano tornou-se genérico quanto a necessidade de produção de AAE's.

AAE 2 - SEÇÃO DE CONCLUSÃO(ÕES)

(9) Unidade: CONCLUIR A PESQUISA

Subunidade $1 \mathrm{~A}$ - apresentando conclusão(ões)

Subunidade 1B - relacionando os resultados à área investigada

Subunidade 2 - apontando contribuição(ões) da pesquisa

Subunidade 3 - apresentando as lacunas da pesquisa

\section{AAE 3 - SECCÃO DE CONCLUSÃO(ÕES)}

(9) Unidade: CONCLUIR A PESQUISA

Subunidade 1A - apresentando conclusão(ões)

Subunidade 1B - relacionando os resultados à área investigada

Subunidade 2 - apontando contribuição(ões) da pesquisa

Subunidade 3 - apresentando as lacunas da pesquisa

Obs.:

Podemos notar que a seção de Conclusão(ões) dos AAE1, AAE2 e AAE3 possuem similaridades (estabilidade relativa) na organização retórica de suas unidades e subunidades, haja vista que os produtores destes AAEs fazem questão de rotular suas considerações, dependendo de uma série de inferências apresentadas, discutidas e interpretadas. Sendo em seu sentido final uma conclusão(ões), pois visa oferecer aos leitores uma constatação feita a partir dos resultados, argumentos ou fatos/achados que puderem identificar nos resultados ou discussão para preencher ou apresentar as lacunas encontradas nessas determinadas investigações científicas.

\section{AAE 4 - SECCÃO DE CONCLUSÃO(ÕES)}

(9) Unidade: CONCLUIR A PESQUISA

Subunidade $1 \mathrm{~A}$ - apresentando conclusão(ões)

Subunidade 1B - relacionando os resultados à área investigada

Subunidade 2 - apontando contribuição(ões) da pesquisa

Subunidade 3 - apresentando as lacunas da pesquisa

\section{AAE 5 - SECCÃO DE CONCLUSÃO(ÕES)}

(9) Unidade: CONCLUIR A PESQUISA

Subunidade $1 \mathrm{~A}$ - apresentando conclusão(ões)

Subunidade 1B - relacionando os resultados à área investigada

Subunidade 2 - apontando contribuição(ões) da pesquisa

Subunidade 3 - ausente no AAE5

\section{AAE 6 - SEÇÃO DE CONCLUSÃO(ÕES)}

(9) Unidade: CONCLUIR A PESQUISA

Subunidade 1A - apresentando conclusão(ões)

Subunidade 1B - relacionando os resultados à área investigada 


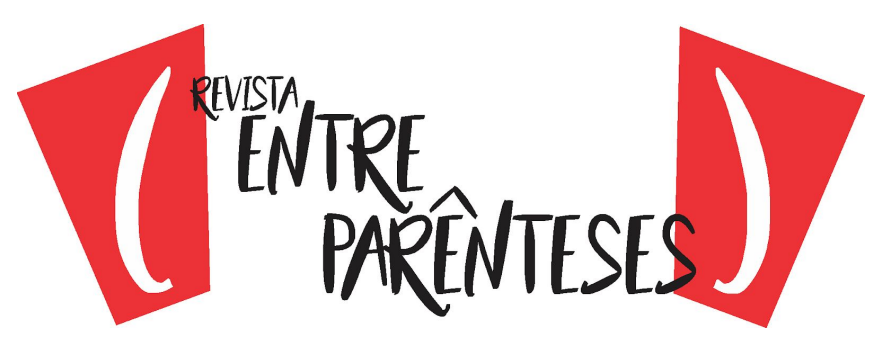

Subunidade 2 - apontando contribuição(ões) da pesquisa

Subunidade 3 - apresentando as lacunas da pesquisa

\section{AAE 7 - SEÇÃO DE CONCLUSÃO(ÕES)}

(9) Unidade: CONCLUIR A PESQUISA

Subunidade 1A - apresentando conclusão(ões)

Subunidade 1B - relacionando os resultados à área investigada

Subunidade 2 - apontando contribuição(ões) da pesquisa

Subunidade 3 - apresentando as lacunas da pesquisa

\section{AAE 8 - SEÇÃO DE CONCLUSÃO(ÕES)}

(9) Unidade: CONCLUIR A PESQUISA

Subunidade 1A - apresentando conclusão(ões)

Subunidade 1B - relacionando os resultados à área investigada

Subunidade 2 - apontando contribuição(ões) da pesquisa

Subunidade 3 - apresentando as lacunas da pesquisa

\section{AAE 9 - SECCÃO DE CONCLUSÃO(ÕES)}

(9) Unidade: CONCLUIR A PESQUISA

Subunidade 1A - apresentando conclusão(ões)

Subunidade 1B - relacionando os resultados à área investigada

Subunidade 2 - apontando contribuição(ões) da pesquisa

Subunidade 3 - ausente no AAE9

\section{AAE 10 - SECCÃO DE CONCLUSÃO(ÕES)}

(9) Unidade: CONCLUIR A PESQUISA

Subunidade 1A - apresentando conclusão(ões)

Subunidade 1B - relacionando os resultados à área investigada

Subunidade 2 - apontando contribuição(ões) da pesquisa

Subunidade 3 - apresentando as lacunas da pesquisa

Considerando que as Conclusão(ões) dos AAEs avaliadas nos forneceram esta importante unidade retórica que objetiva concluir a pesquisa, apresentando as conclusão(ões) relacionadas aos resultados da área investigada, sendo também apontada(as) a(as) contribuição(ões) da pesquisa. Enfim, é neste momento que se apresentam as lacunas da pesquisa oriundas das discussões e considerações sobre os dados e os fatos/achados da pesquisa nas seções anteriores dos AAEs.

Os esquemas-síntese acima feitos, a partir da análise das unidades e subunidades retóricas de Conclusões de AAEs, são estratégias de condução das informações dos AAEs que servem como referência para as observações que 


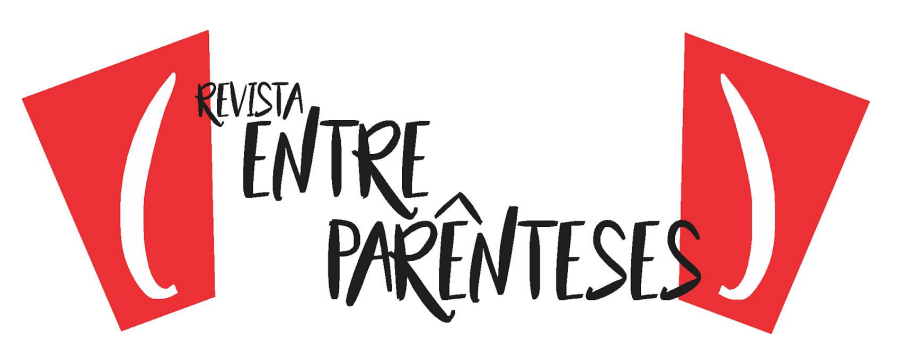

fizemos a seguir nos artigos acadêmicos experimentais. A partir disso, identificamos as semelhanças e/ou diferenças encontradas nos próximos exemplares de AAEs desta pesquisa, para que a análise não se torne repetitiva e se priorize pela essencialidade de preencher as lacunas presentes neste estudo.

Observamos que as 10 conclusões de AAEs possuem unidades retóricas relativamente estáveis em consonância com o modelo descritivo de organização retórica que formulamos a partir da análise inicial do corpus de 10 AEEs advindos da aplicação do modelo CARS de Swales (1990). A seguir apresentamos a distribuição das unidades e subunidades sociorretóricas dos AAEs em porcentagem:

Tabela 1 - Distribuição das unidades e subunidades retóricas dos AAEs em porcentagem

\begin{tabular}{|l|c|c|}
\hline \multicolumn{1}{|c|}{$\begin{array}{l}\text { ANIDADES E SUBUNIDADES RETÓRICAS DOS } \\
\text { AAEs }\end{array}$} & No DE OCORRÊNCIA & \% \\
\hline $\begin{array}{l}\text { UNID. 9: CONCLUIR A PESQUISA } \\
\text { Sub 1A - Apresentando conclusão(ões) }\end{array}$ & 10 & 100 \\
\hline $\begin{array}{l}\text { Sub 1B - Relacionando os resultados à área } \\
\text { investigada }\end{array}$ & 10 & 100 \\
\hline Sub 2 - Apontando contribuição(ões) da pesquisa & 09 & 90 \\
\hline Sub 3 - Apresentando as lacunas da pesquisa & 10 & 100 \\
\hline
\end{tabular}

Fonte: elaborado pelo autor

\section{Descrição e análise das unidades e de suas respectivas subunidades sociorretóricas das seções de conclusão dos AAEs}

Os autores/produtores dos AAEs, ao escrevem seus posicionamentos conclusivos, procuram alertar os leitores sobre as lacunas oriundas da pesquisa e que precisarão ainda ser investigadas em outras pesquisas posteriormente. Por isso, eles/elas se utilizam de algumas expressões léxico-gramaticais para externar suas conclusões/considerações finais sobre as lacunas que foram deixadas ou que ele ou os demais membros da comunidade acadêmica possam realizar um trabalho de 


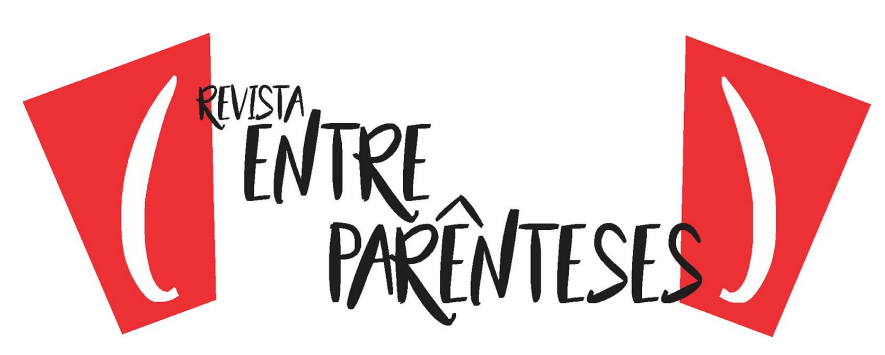

investigação que possa suprir essa necessidade do conhecimento disciplinar de seus pares.

\section{Unidade retórica $9^{12}$ : Concluir a pesquisa}

Esta Un9 evidenciou também uma estabilidade relativa, ocorrendo em todos (100\%) os exemplares do corpus de AAEs (AAE1, AAE2, AAE3, AAE4, AAE5, AAE6, AAE7, AAE8, AAE9 e AAE10). A Un9 tem uma função bastante clara nos artigos acadêmicos experimentais que analisamos devido à necessidade comunicativa que os alunos demonstraram ter em relação ao leitor, buscando concluir seus posicionamentos de acordo com os resultados que conseguiram alcançar.

Esses autores/produtores, destarte, fazem deferência aos conteúdos informacionais das seções anteriores, com o fim de apontar as consequências, resultados, contribuições e o modo como os objetivos do trabalho foram resolvidos ao longo da pesquisa. Por fim, constatamos que os alunos, ao produzirem seus textos, procuraram expor as lacunas que a pesquisa apresentou, indicando muitas vezes recomendações(ões)/sugestões para a produção de outras pesquisas além das já realizadas por eles. Sabemos ainda que geralmente esta Un9 retoma aspectos da seção Introdução, como questões-problemas, objetivos e hipóteses que foram resolvidas ou não pela metodologia e a aplicação desta na seção de Resultados e Discussão para se conseguir os resultados estabelecidos.

\section{Subunidade 1A - Apresentando conclusão(ões)}

Esta Sub1A está presente em todos (100\%) os exemplares do corpus de AAEs (AAE1, AAE2, AAE3, AAE4, AAE5, AAE6, AAE7, AAE8, AAE9 e AAE10). A

\footnotetext{
12 Ver Modelo de Análise de Gênero, de Paiva e Duarte (2017, p. 389). In: http://www.olhodagua.ibilce.unesp.br/index.php/revistamosaico/article/view/430/422. Acesso em 17/04/2018.
} 


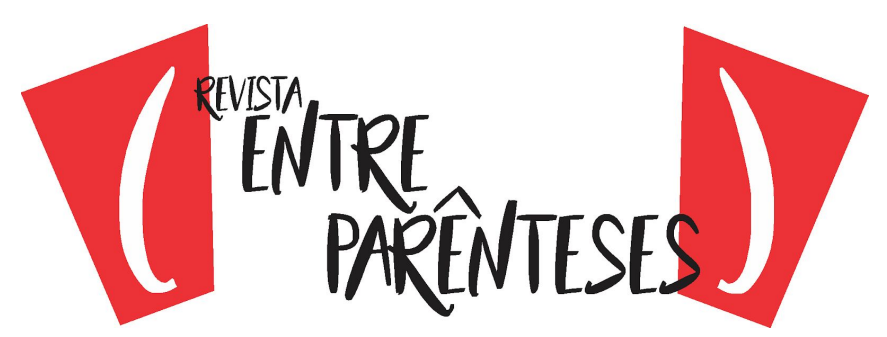

Sub1A objetiva apresentar as conclusões, evidenciando-se pela clareza e objetividade as deduções extraídas dos resultados obtidos ou apontados ao longo da discussão do assunto. Caracteriza-se por fazer considerações resultantes da pesquisa como um todo e por extrapolar o seu âmbito, às vezes comparativamente, ou mostrando vantagens, entre outras possibilidades, e geralmente é marcada pelo item lexical 'conclusão', 'conclui-se', 'concluímos' ou alguma expressão similar como se pode conferir nos exemplos abaixo:

[AAE1] Diante de todos os argumentos aqui discutidos, [concluímos] que a construção estético-literária do personagem Mariano nos propiciou uma gama de elementos narrativos que, ao longo do romance, foram bem encandeados, [por isso] analisamos esses aspectos em conformidade com a produção discursiva e pelo dialogismo intermediado textualmente pelas características e decepções que teve, ao tentar construir relações familiares, inicialmente com Percília e, depois com Nazaré, [sendo que] a última foge, deixando-o transtornado e cheio de mágoas, ressentimentos e revoltas de si mesmo. (p.11).

[AA6] Em [conclusão] entendemos que a utilização adequada de hiperônimos e hipônimos na construção da coesão lexical favorece consideravelmente para a existência de novas relações substitutivas e sintagmáticas de sentidos entre os lexemas escritos pelos alunos da $5^{a}$ série do Ensino Fundamental, [já que] há uma predominância no emprego de nomes genéricos para retomar um referente anterior, caracterizando-o com exatidão e possibilitando que haja uma construção de relações de sentidos nos textos reescritos pelos alunos. (p.10).

Está verificado acima que os alunos, ao apresentarem a conclusão(ões) dos AEEs que escreveram, procuraram expor algumas considerações resultantes das seções anteriores, sendo que o objeto de estudo foi retomado no sentido de se ter uma posição final do que foi deduzido pela pesquisa, a fim de que o leitor seja esclarecido sobre as vantagens teóricas e/ou metodológicas que foram alcançados pelo estudo desenvolvido.

\section{Subunidade 1B - Relacionando os resultados à área investigada}

Esta Sub1B está presente em todos (90\%) os exemplares do corpus de AAEs (AAE1, AAE2, AAE3, AAE5, AAE6, AAE7, AAE8 e AAE10). Esta Sub1B tem a 


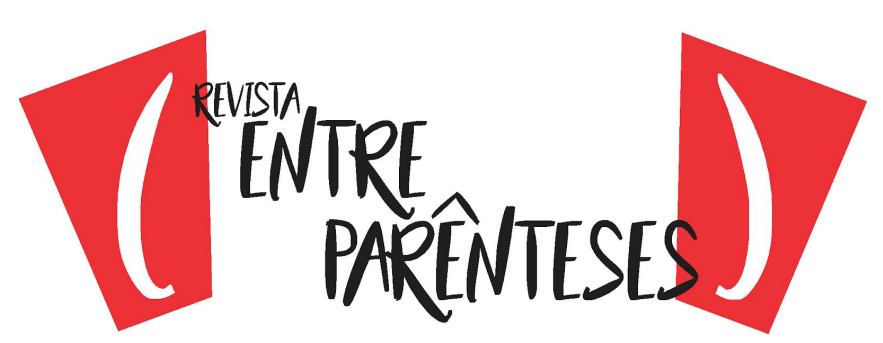

subfunção de fazer uma relação dos resultados alcançados com a área de investigação, explicando alguns resultados que foram produto da análise do corpus ou amostra de pesquisa, para que o leitor possa perceber essa relação de maneira perceptível de acordo com as informações são apresentadas pelos AAEs.

Podemos observar esses argumentos acima através dos excertos abaixo:

[AAE10] [Constatamos também que] os alunos precisam ter contato com materiais acadêmicos mais direcionados [a desenvolver a competência de escrita de resenhas]. Faz-se lembrar, entretanto, que ninguém se pode considerar perfeito nesse tipo de tarefa, [porque] a arte de produzir tais gêneros textuais constrói-se na prática de pesquisa, extensão e atividades acadêmicas através da experiência e da adaptação aos aspectos culturais da comunidade discursiva que se está inserido. (p.20).

[AAE3] [Assegura-se, a partir daqui, que] a escola é tomada como um autêntico lugar de comunicação e as situações escolares são fundamentais como ocasiões de produção/recepção de textos. [Dessa forma], no ambiente escolar, a produção de textos deve inserir-se num processo de interlocução - o que implica uma série de atividades mentais - de planejamento e de execução - que não são lineares e nem estanques, mas recorrentes e interdependentes. (p.21).

As implicações de análise acima demonstraram realmente que os autores/produtores dos AAEs explicaram os resultados, mas de uma forma ou de outra, tentando relacioná-los à área de investigação científica que o objeto foi avaliado na seção Resultados e Discussão dos AAEs. Observamos que os itens lexicais ou expressões nos excertos acima ilustram, de fato, essa relação dos resultados com a área investigada: 'constatamos também que', 'assegura-se, a partir daqui, que', 'essas constatações', são exemplos claro dessa subfunção no ato retórico de estar prestes a concluir a pesquisa.

\section{Subunidade 2 - Apontando contribuição(ões) da pesquisa}

Esta Sub2 está presente em todos (100\%) os exemplares do corpus de AAEs (AAE1, AAE2, AAE3, AAE4, AAE5, AAE6, AAE7, AAE8, AAE9 e AAE10). A Sub2 objetiva apontar as contribuições resultantes dos procedimentos de análises que foram aplicados, sendo que nesse momento os alunos procuraram esclarecer 


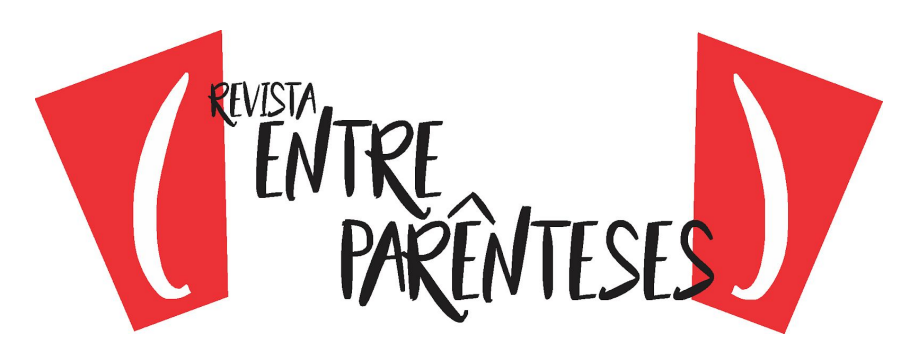

para os leitores dos AAEs quais foram os resultados da pesquisa que tiveram uma importância para o engrandecimento da pesquisa num determinado domínio discursivo, abrindo possibilidades para que outras aplicações posteriores sejam feitas a partir dos fatos/achados encontrados.

Confiramos esses apontamentos acima nos exemplos abaixo:

[AAE2] [Propõe-se], em virtude dos pressupostos teórico-metodológicos aqui indagados e respondidos empiricamente pela análise das redações e questionários aqui propostos como forma de verificação científica, que [o professor enquanto mediador do ensino-aprendizagem de Língua Portuguesa], precisa oferecer aos alunos condições reflexivas e mais atuantes de avaliação e reescritura de textos, para que se examine os elementos linguístico-textuais contidos na estruturação semântico-lexical de suas produções que favoreça num maior aprendizado e rendimento escolar. (p.10).

[AAE5] [Por isso], observamos nesta análise que poucas moficações foram realizadas por Truffaut no filme, por exemplo, a ausência do professor Faber, [...], o autor usou uma caixa postal metálica [para que] as pessoas pudessem denunciar os vizinhos e até os mais próximos sobre práticas ilegais e contra a ordem pública. (p.5).

Ficou certo pelos exemplos acima que autores/produtores dos AAEs objetivaram apontar para os leitores algumas contribuições que a pesquisa possibilitou, explicando que as hipóteses e questões-problema foram respondidas por intermédio dos subsídios teóricos e/ou metodológicos advindos da realização empírica da pesquisa realizada pelos sujeitos de pesquisa.

É interessante que houve uma estabilidade relativa desta Sub2 nas seções de Conclusão dos AAEs que selecionamos para este estudo. Porque segundo Biasi-Rodrigues (1998, p.128), nesta "unidade inclui também considerações finais que são comuns em encerramentos de textos acadêmicos, tais como contribuições e recomendações ou sugestões". Sendo, assim, nos AAEs existe uma preocupação de retomar as hipóteses relacionadas a fatos que as sustentam ou contestam, fazendo com que as contribuições da pesquisa sejam explicitadas ao leitor com mais intensidade e recorrência textual. 


\section{("Wing}

Subunidade 3 - Apresentando as lacunas da pesquisa

Esta Sub3 da seção de Conclusão dos AAEs finaliza a Un9 deste modelo de organização retórica das informações nos artigos acadêmicos experimentais de alunos iniciantes do curso de Graduação em Letras, tendo uma pequena variação em sua ocorrência, e apareceu em sete $(80 \%)$ dos dez AAEs do corpus (AAE1, AAE2, AAE3, AAE4, AAE6, AAE7, AAE8). A Sub3, diferentemente da Sub1B da seção de Introdução que visa indicar lacunas no conhecimento, tem a subfunção relacionada a apresentar as lacunas que a pesquisa como um todo não conseguiu ainda preencher ou precisará explorar em outros estudos. Apenas três exemplares apresentaram ausência desta Sub3: AAE5, AAE9 e AAE10.

Podemos observar esses argumentos acima através dos excertos abaixo:

[AAE3] [Faz-se indispensável uma discussão cientificamente mais aprofundada] pelos educadores de Língua Portuguesa com os de outras áreas para que novas metodologias sejam estratificadas, reformulando as práticas já usadas como forma de verificar a realidade sociocultural do aluno, (...). [Para que] haja uma decisão mais consistente e produtiva do ensino da língua, criando, estimulando e oportunizando o educando a produzir textos e a leitura constante. (p.21).

[AAE8] Em síntese, [diríamos] que a enunciação em Vandré privilegia o lado "objetivo" da cultura (pela convocação das figuras já "dicionarizadas"), [ao passo que] Caetano privilegia o seu lado "subjetivo" (pela "dessemantização" das mesmas figuras); em ambos os casos, entretanto, é fundamental o recurso ao mesmo "dicionário" figurativo. (p.14).

Em outras palavras, esta Un9 por ter uma missão crucial ao tecer posicionamentos conclusivos, atendendo, pois, a uma necessidade comunicativa que os alunos iniciantes do curso de Graduação em Letras da Fafidam têm, ao produzirem essa modalidade de artigo acadêmico, demonstraram ter em relação ao leitor uma preocupação explícita em retomar os resultados alcançados pela pesquisa, procurando relacioná-los à área em que se pretendeu estudar.

Desse modo, fazem, nesse processo de condução das informações, uma alusão às contribuições, recomendações e sugestões que são feitas ao leitor dos AAEs, buscando, enfim, concluir seus posicionamentos de acordo com os 


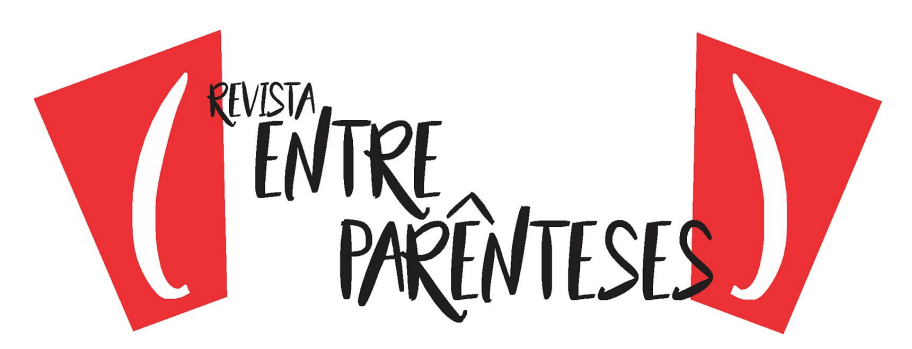

resultados, fazendo uma apresentação das lacunas que esses resultados ainda não conseguiram resolver ou preencher, logo serão necessárias outras investigações científicas entre seus pares.

\section{Conclusão(ões)}

Dessa forma, embora não fosse o objetivo central de nossa investigação, acabamos por apresentar alguns aspectos que sustentam os posicionamentos conclusivos obtidos com o fim de formalizar um padrão de organização sociorretórica das unidades e subunidades presentes no corpus de 10 AAEs produzidos por esses produtores concludentes na academia. Como há ainda poucos estudos no espaço das práticas de produção escrita de gêneros discursivos acadêmicos que tenham formalizado um modelo descritivo da modalidade de artigos acadêmicos, dispomo-nos a analisar e a descrever AAEs de alunos concludentes do curso de Letras.

Então, esta pesquisa, ao basear-se em um corpus composto por 10 AAEs de alunos do Curso de Graduação em Letras, colhido nas atividades de pesquisa realizadas em disciplinas desse curso, buscamos contextualizar sua produção, o uso e a circulação desses gêneros textuais acadêmicos nessa comunidade discursiva, procurando descrever sua organização sociorretórica e explicitando os propósitos comunicativos, aspectos estilísticos caraterizadores e estrutura composicional com a aplicação do modelo CARS de Swales (1990).

Um fato interessante é que as seções Conclusões avaliadas apresentaram grande estabilidade relativa de suas unidades e subunidades sociorretóricas, tendo em vista que os postulados teóricos que fundamentam dizem que essas seções são recorrentes na composição textual de artigos acadêmicos experimentais. Vejamos a seguir o modelo formatado a partir da pesquisa realizada com fins de compilar os excertos das Conclusões dos AAEs selecionados: 


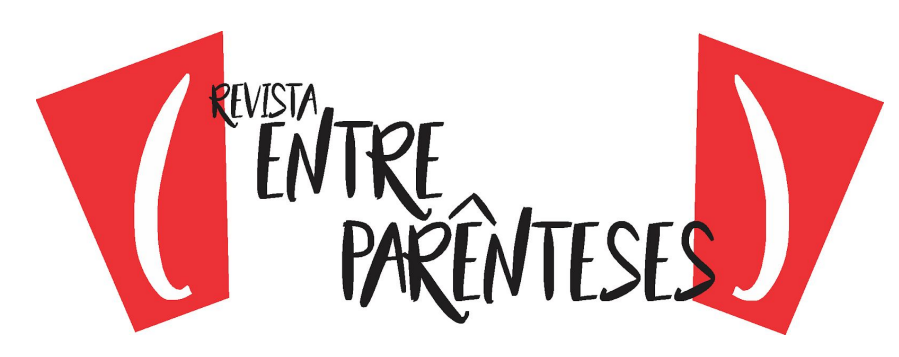

Ficou patente que a frequência de unidades e subunidades sociorretóricas nas Conclusão(ões) dos AAEs apresentaram uma expressiva recorrência em relação ao número total de artigos acadêmicos experimentais selecionados, embora apresente alguma variação de recorrência em suas subunidades.

Podemos, enfim, verificar ainda que essa estabilidade de unidades e subunidades sociorretóricas constitui um indício de convencionalidade da escrita acadêmica em detrimento das escolhas dadas pelos autores às unidades sociorretóricas e subunidades que selecionam para compor os AAEs, esse fato pode representar a cultura acadêmica, que possivelmente é restrita a esse espaço de produção discursiva, ou pode ser resultado do (des)conhecimento das convenções praticadas nesse domínio, tomados como parâmetros para a organização retórica de textos acadêmicos.

\section{Referências}

ARAÚJO, Antonia Dilamar. Lexical signalling: a study of unspecific-nouns in book reviews. Tese (Doutorado em Linguística). Universidade Federal de Santa Catarina, Florianópolis, 1996.

Práticas discursivas em conclusões de teses de doutorado. Revista Linguagem em (Dis)curso, volume 6, número 3, set./dez. 2006.

ASKEHAVE, I.; SWALES, J. M. Genre indentification and communicative purpose: a problem and a possible solution. Applied Linguistics, v.22, n.2, p. 195-212, 2001.

BAKHTIN, Mikhail. Marxismo e filosofia da linguagem. São Paulo: Hucite, 1979.

. Os gêneros do discurso: estética da criação verbal. São Paulo: Martins Fontes, [1953] 1992.

. Os gêneros do discurso: estética da criação verbal. 2. ed. São Paulo: Martins Fontes, [1952-1953] 1997. p. 279-326. 


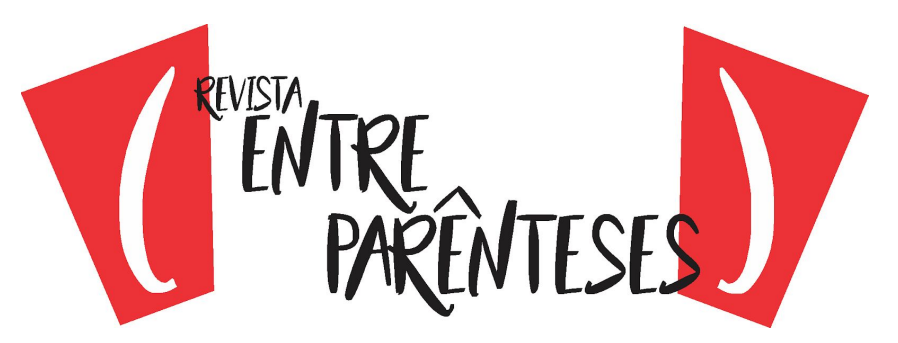

Os gêneros do discurso: estética da criação verbal. 2. ed. Trad. Paulo Bezerra). São Paulo: Editora Unesp, 2003.

BERNARDINO, Cibele Gadelha. 0 metadiscurso interpessoal em artigos acadêmicos: espaço de negociações e construção de posicionamentos. 2007. $243 f$. Tese (Doutorado em Linguística Aplicada). Belo Horizonte: Universidade Federal de Minas Gerais, 2007.

BEZERRA, Benedito Gomes. Gêneros introdutórios em livros acadêmicos. 2006. 256f. Tese (Doutorado em Linguística). Pernambuco: Universidade Federal de Pernambuco, 2006.

BIASI-RODRIGUES, B. Estratégias de condução de informações em resumos de dissertações. 1998. 211f. Tese (Doutorado em Linguística). Universidade Federal de Santa Catarina, 1998.

BHATIA, V. K. Analysing Genre: language use in professional settings. London: Longman, 1993.

BRAIT, B. "Análise e teoria do discurso". In: BRAIT, B. (Org.). Bakhtin - outros conceitos-chave. São Paulo: Contexto, 2006.

CAVALCANTI, M.C. Itens lexicais chaves como fios condutores semântico-pragmáticos na interação leitor-texto. In: FÁVERO, L.L. PASCHOAL, M.S.Z. (orgs.). Linguística textual: texto e leitura. São Paulo: EDUC, 1985, p. 171-184.

CHOULIARAKI, L.; FAIRCLOUGH, N. Discourse in late modernity: Rethinking critical discourse analysis. Edinburgh: Edinburgh University Press, 1999.

DODD, J. The ACS style guide: a manual for authors and editors. Washington, DC: Library of Congress in Publication Data, 1986.

FAIRCLOUGH, N. Discourse and social change. Cambridge: Polity Press, 1992.

HEMAIS, B.; BIASI-RODRIGUES, B. Princípios teóricos metodológicos para análise de gêneros na perspectiva de J. M. Swales. In: MEURER, V. L.; BONINI, A.; MOTA-ROTH, D. Gênero: teorias métodos e debates. São Paulo: Parábola, 2005.

HENDGES, G. R. Novos contextos, novos gêneros: a revisão de literatura em artigos acadêmicos eletrônicos. 2001. 126f. Dissertação (Mestrado em Letras). Santa Maria, Universidade Federal de Santa Maria, 2001.

HYLAND, K. Disciplinary discourse: social interactions in academic writing. Singapura: Pearson Edacation Limited, 2000. 


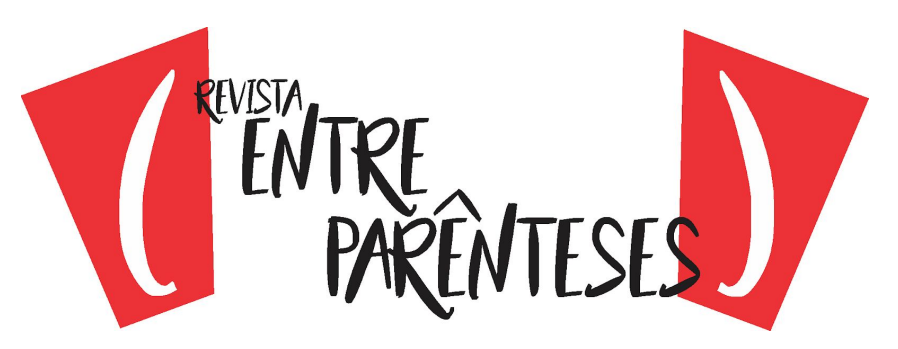

JUCÁ, D. C.N. A organização retórico-argumentativa da seção de justificativa no gênero textual Projeto de Dissertação. 2006. 109f. Dissertação (Mestrado em Linguística). Fortaleza: Universidade Federal do Ceará - UFC, 2006.

KNORR-CETINA, K.D. The manufacture of knowledge. Oxford: Pergamon, 1981.

LAKATOS, E. M.; MARCONI, M. A. Fundamentos de Metodologia Científica. 6. ed. São Paulo: Atlas, 2007.

MACHADO, I. Gêneros discursivos. In: BRAIT, B. (Org.). Bakhtin: conceitos-chave. São Paulo: Contexto, 2005.

MAINGUENEAU, D. Análise de textos de comunicação. (Tradução de Cecília P. de Souza-e-Silva e Décio Rocha). São Paulo: Cortez, 2001.

MARCUSCHI, L. A. A questão metodológica na análise da interação verbal: os aspectos qualitativo e quantitativo. IV Encontro Nacional de Interação em Linguagem Verbal e Não-Verbal: Metodologias Qualitativas, Universidade de Brasília, 22-24 de abril, 1999.

- Gêneros Textuais: definição e funcionalidade. In: DíONISIO, A. P. et al. Gêneros Textuais e Ensino. Rio de Janeiro: Lucerna, 2002.

MOTTA-ROTH, D. Rhetorical features and disciplinary cultures: a genre based study of academic book reviews in linguistics, chemistry, and economics. 1995. $356 f$. Tese (Doutorado em Linguística Aplicada). Universidade Federal de Santa Catarina, Florianópolis, 1995.

- Redação acadêmica: princípios básicos. Santa Maria: UFSM/Imprensa Universitária, 2001.

A construção social do gênero resenha acadêmica. In: MEURER, J. L. \& MOTTA-ROTH, D. (Orgs.). Gêneros textuais: subsídios para o ensino da linguagem. Bauru: EDUSC, 2002. p.77116, 2002b.

MONZÓN, A. J. B. Construção de banco de questões para exames de proficiência em inglês para programas de pós-graduação. 2009. $152 f$. Dissertação (Mestrado em Linguística). São Carlos: UFSCar, 2009.

OLIVEIRA, A. C. A. de. Memorial Acadêmico: contexto comunicativo-situacional de produção e organização retórica do gênero. 2005. 184f. Dissertação (Mestrado em Linguística). Fortaleza: Universidade Federal do Ceará - UFC, 2005. 


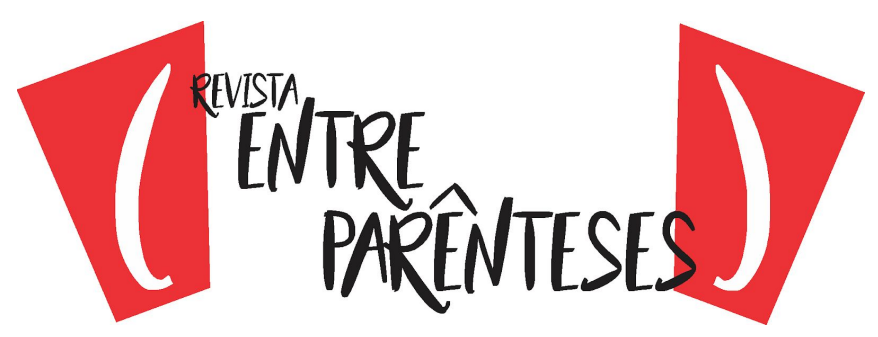

PAIVA, F. J. de O. Artigo Acadêmico Experimental: uma análise da experiência de escrita de alunos iniciantes do Curso de Letras da UECE, campus Limoeiro do Norte (FAFIDAM). 2011. 166f. Monografia (Licenciatura Plena em Língua Portuguesa e suas respectivas Literaturas). Limoeiro do Norte-CE: Faculdade de Filosofia Dom Aureliano Matos, UECE, 2011.

DUARTE, A. L. M. Uma análise do artigo acadêmico experimental: as práticas discursivas e as experiências de escrita de alunos iniciantes do curso de letras. Mosaico (Instituto de Biociências, Letras e Ciências Exatas - UNESP), São José do Rio Preto, SP - Brasil, 2017, pp. 374-402.

SWALES, J. M. the function of one type participle in a chemistry text. In: BIASI-RODRIGUES, B.; ARAÚJO, J.C.; SOUSA, S.C.T. de. (Orgs). Gêneros textuais e comunidades discursivas: um diálogo com John Swales. Belo Horizonte: Autentica Editora, p. 17-32, 2009.

Genre analysis: English in academic and research settings. Cambridge: University Press, 1990.

Re-thinking genre: another look at discourse community effects. Comunicação apresentada em Re-thinking Genre Colloquium, Ottawa: Carleton University, 1992.

687-698, 1993.

Genre and engagement. Revue belge de philology et d'historie, v. 71, p.

Other floors, other voices: a textography of a small university building. Mahwah, N.J.Lawrence Erbaum, 1998.

University $P$

Research genres: explorations and applications. Cambridge: Cambridge

Recebido em 16/04/2018.

Aceito em 27/08/2018. 